\title{
REAL-TIME MONITORING SYSTEM FOR USED MWFS
}

\author{
Kristína Gerulová, Tomáš Škulavík, Eva Buranská \& František Jurina
}
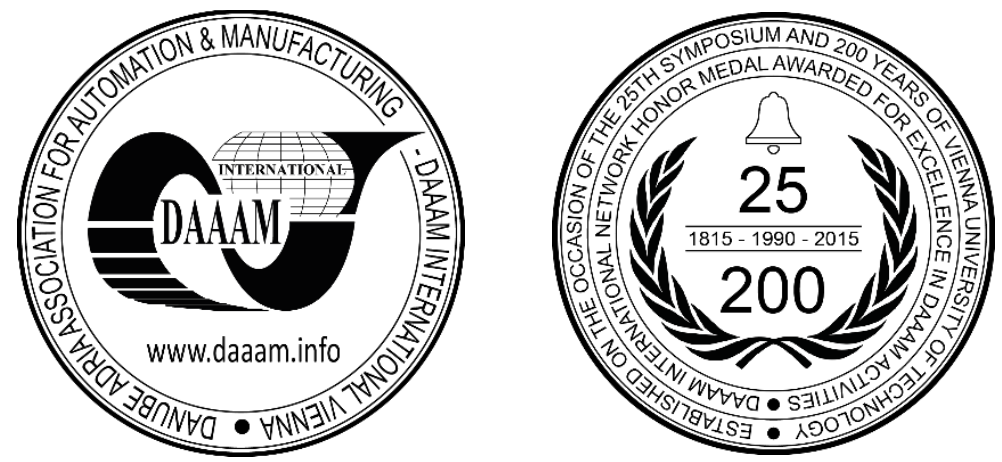

This Publication has to be referred as: Gerulova, K[ristina]; Skulavik, T[omas]; Buranska, E[va] \& Jurina, F[rantisek] (2018). Real-Time Monitoring System for Used MWFs, Proceedings of the 29th DAAAM International Symposium, pp.1148-1157, B. Katalinic (Ed.), Published by DAAAM International, ISBN 978-3-902734-20-4, ISSN 1726-9679, Vienna, Austria

DOI: $10.2507 / 29$ th.daaam.proceedings. 165

\begin{abstract}
Measuring biodegradability of poorly soluble substances according to the standardized test methods where the carbon dioxide captured in the absorption solution is the main parameter is time consuming and needs manual analysis. To overcome these problems, it was used a modified closed apparatus consist of two bottles - reaction bottle where the biodegradability takes place and absorption bottle where the carbon dioxide produced by the microbial inoculum is trapped. For the measurement of trapped carbon dioxide it is utilize the fact that the barium carbonates precipitate, which is the result of simple chemical reaction, decrease conductivity of the absorption solution linearly. To allow synchronized measurement of 8-12 apparatuses a real-time monitoring interface for recording conductivity of 8-12 probes was constructed and tested with the standard substance glucose during 14 days of continual measurements. Self-developed interface showed its full applicability in the biodegradability testing. A substance with at least $80 \mathrm{ppm} \mathrm{C}$ may be assessed by this method.
\end{abstract}

Keywords: Real time; Conductivity; Probes; Interface; A/D converters

\section{Introduction}

There are standardized many methods for assessing biodegradability of organic substances. Testing method selection is a choice of number of conditions. When testing a known substance direct analytical methods may be useful. It is possible to assess decreasing of the parent compound concentration and increasing concentration of the degradation intermediates. When a mixture of soluble substances is under evaluation, there are three main ways to choose. First, analysis of the parent compounds and intermediates may be time consuming sometimes impossible depends on the components number. Second is the indirect measurement of summary parameters of organics such as COD (Chemical oxygen demand), TOC (total organic carbon), DOC (dissolved organic carbon) etc.

In these methods only the organic load decreasing may be assessed while nothing is known about the intermediates created in the system and nothing is known about their impact on used inoculum. Third group of methods include the indirect measurement of the bacteria utilized for the biological oxidation. If substances in the mixture are utilized by microorganism as a source of organic carbon and energy, they consume oxygen and release carbon dioxide. Oxygen from the closed system may be recorded so produced carbon dioxide. 
There exist at least three biodegradability tests which are based on the indirect measurement of bacteria's activity and where the measured parameter is evolved carbon dioxide. These tests include OECD 301 B [2] or equivalent C.4-C Reach method [3], ASTM 6139-11 [4] and ASTM 5864-11 [5]. Joint characteristic of these tests is that the carbon dioxide free air is passed through the reactor containing inoculum while the carbon dioxide produced by the microorganisms during the biodegradation is trapped in the absorption solution and discontinuously measured in defined time interval (previously described in [6]). Measurements of carbon dioxide produced by the inoculum commonly include time consuming manual titrating methods. Biodegradability measurements usually take few weeks (2-4 weeks), while the system failures are not controllable in real time.

Last updates of selected standardized methods allowed also the use of gas $\mathrm{CO}_{2}$ analysers but these may be high in investments. It was firstly published by Norr and Strotmann in [1,7] that captured carbon dioxide can be measured by conductivity probes immersed in the absorption solution of barium hydroxide. This bring in to the long term biodegradability tests the possibility of real time monitoring and control of the whole process while the measurement is easy, does not require day-to-day time-consuming analysis or high investments while remain still precise. Because of need of parallel measurements, 12 channel microprocessor controlled data acquisition and processing device was developed. An RS-485 communication interface was implemented to the device, to prevent the data loss during the transfer in harsh environment to PC.

The measuring device was equipped with SRAM and a super capacitor which together allows the internal measured data storing. This prevents the data loses not only during the communication failure but also after a HMI crash. The human machine interface (HMI) could be a basic PC with windows operation system and a USB communication port.

\section{Modified Biodegradability apparatus}

\subsection{The principle of the biodegradability measurement where the evolved $\mathrm{CO}_{2}$ is measured as the main parameter}

For better understanding the complexity of the apparatus for the biodegradability measurement of poorly soluble substances e.g. in the ASTM 5864-11 a simple schema is shown in the Fig. 1.

\section{ASTM D5864-11}

Standard test Method for Determining Aerobic Aquatic Biodegradation of Lubricants or Their Components

\section{Incubation Apparatus for $\mathrm{CO}_{2}$ Evolution \\ Test substance/Blank/Standard in Triplicates \\ $\mathrm{CO}_{2}$ produced by microorganisms during the degradation process \\ $4 \mathrm{~L}$ Erlenmeyer flasks}

$\mathrm{CO}_{2}$ Scrubbing Apparatus

$\mathrm{CO}_{2}$ removing from the air

$1 \mathrm{~L}$ Erlenmeyer flasks

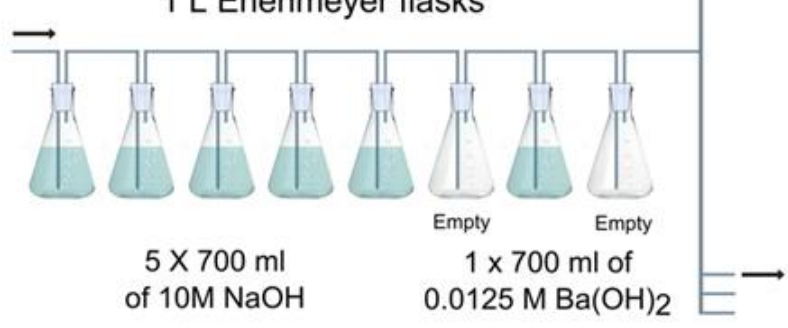

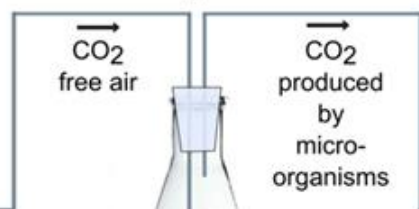

$\mathrm{CO}_{2}$ Tapping Apparatus

$\mathrm{CO}_{2}$ measuring by titration methods

$200 \mathrm{~mL}$ Erlenmayer flasks
Test substance:

$10-20 \mathrm{mg} \mathrm{C/L}$

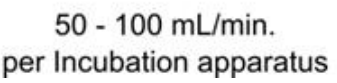

\section{0 mL Ellenmayer flasks}

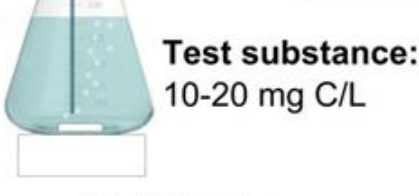

per Incubation apparatus

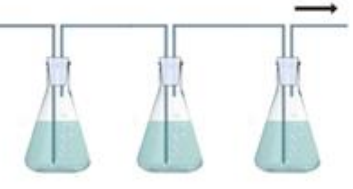

$3 \times 100 \mathrm{ml}$ of $0.0125 \mathrm{M}$

Fig. 1. Schema of the apparatus for the Biodegradability measurement of Lubricants according to ASTM 5864-11 [6]

The whole system works at normal pressure. Carbon dioxide free air prepared in the $\mathrm{CO}_{2}$ scrubbing apparatus is bubbled through the incubation apparatus and here $\mathrm{CO}_{2}$ produced by the microorganisms is after captured in the tapping apparatus contained solution of barium hydroxide. Carbon dioxide is the main parameter by which the biodegradability of tested substance is calculated.

\subsection{The principle of the modified apparatus}

Modified apparatus for biodegradability measuring consist of two equal glass bottles connected by the peristaltic pump (Fig. 2). 


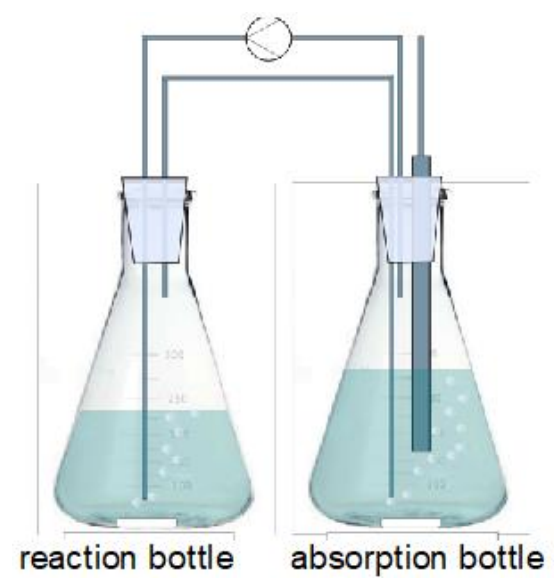

Fig. 2. Simple schema of modified Biodegradability apparatus

This closed circulation system ensures pumping the air part from the reaction bottle where the biodegradation takes place to the absorption bottle where the produced carbon dioxide is trapped. Because the typical test for the biodegradation needs at least one separate apparatus for the blank (inoculum endogenous respiration measurement), one for the control (containing standard substance with defined biodegradation) and 3 for the sample it was constructed a biodegradation system contains of 8 separate apparatuses with the possibility to expand it to 12 .

\subsection{The principle of the trapped carbon dioxide calculation according to the recorded change in absorption solution conductivity}

As it was previously mentioned carbon dioxide produced by the inoculum during the utilization of tested organic substance is trapped in the conductive solution of barium hydroxide predominantly, while the reaction (1) takes place:

$$
\mathrm{Ba}(\mathrm{OH})_{2}+\mathrm{CO}_{2} \rightarrow \mathrm{BaCO}_{3}+\mathrm{H}_{2} \mathrm{O}
$$

As the insoluble precipitate of barium carbonate is form the conductivity of the solution decrease. As it is seemed from the calibration curves (Fig. 3) the conductivity of absorption solution linearly decreases with the amount of captured carbon dioxide for both conductivity probes measurement range $(0-20.0 \mathrm{mS} / \mathrm{cm}$ and $0-2.0 \mathrm{mS} / \mathrm{cm}$ while different concentrations of barium hydroxide were used in the calibration). During the real experiment the system needs to be refilled with fresh solution of absorption solution when the conductivity decreases to $2.0-3.0 \mathrm{mS} / \mathrm{cm}$ to not affected the microbial inoculum by the exhausting the system from oxygen occurred in the closed environment and change conditions inside the apparatus because of change in pressure.

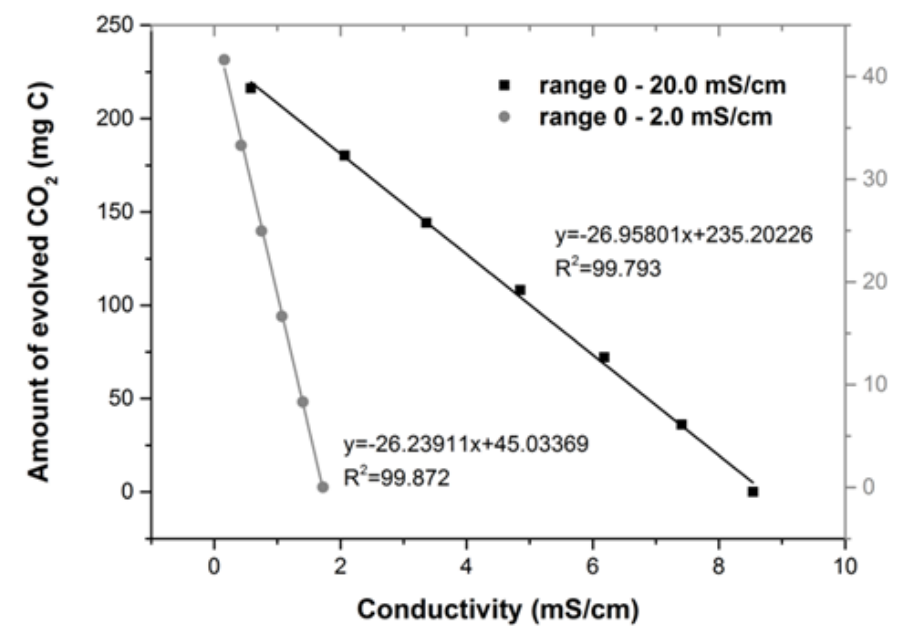

Fig. 3. Calibration curves for different conductivity probe ranges

For the calibration curve a defined amount of carbon dioxide produced by the chemical reaction between sodium carbonate and hydrochloric acid according to (2) was used to record the change in conductivity of absorption solution:

$$
\mathrm{Na}_{2} \mathrm{CO}_{3}+2 \mathrm{HCl} \rightarrow 2 \mathrm{NaCl}+\mathrm{CO}_{2}+\mathrm{H}_{2} \mathrm{O}
$$


The amount of absorbed $\mathrm{CO}_{2}$ as mg C during defined time interval for the test/control/blank apparatus is calculated as a difference between the $\mathrm{CO}_{2}$ amount in the absorption solution at the time $t$ and the $\mathrm{CO}_{2}$ amount in the absorption solution at the start of the test $t_{0}$ according to (3)-(5).

$$
\begin{aligned}
& m_{\mathrm{CO}_{2}}=m_{\mathrm{CO}_{2}(t 0)}-m_{\mathrm{CO}_{2}(t)} \\
& m_{\mathrm{CO}_{2}}=26.95801\left(x_{t 0}-x_{t}\right)
\end{aligned}
$$

For the conductivity range $0-20 \mathrm{mS} / \mathrm{cm}$, and

$$
m_{\mathrm{CO}_{2}}=26.23911\left(x_{t 0}-x_{t}\right)
$$

For the conductivity range $0-2 \mathrm{mS} / \mathrm{cm}$, where, $m_{\mathrm{CO}_{2}}$ is the amount of absorbed $\mathrm{CO}_{2}$ at time $t$ for the test/control/blank apparatus in $\mathrm{mg} \mathrm{C} ; x_{t 0}$ is the conductivity of the absorption solution at the start of the test for the test/control/blank apparatus in $\mathrm{mg} \mathrm{C} ; x_{t}$ is the conductivity of the absorption solution at the time $t$ of the test for the test/control/blank apparatus in $\mathrm{mg} \mathrm{C}$.

\subsection{The capacity of absorption solution and oxygen content}

In the real biodegradability test it is usually used $1 \mathrm{~L}$ of $\mathrm{Ba}(\mathrm{OH})_{2}(0.0175 \mathrm{~mol} / \mathrm{L})$ which is normally conductive and achieve conductivity $7.5 \pm 0.1 \mathrm{mS} / \mathrm{cm}$. The total capacity of this solution to absorb carbon dioxide (taking into account (1)) is estimated to $210 \mathrm{mg} \mathrm{C}$. It means that theoretically a substance with this amount of carbon after complete utilization by the microbial inoculum may be measured without system refilling with the fresh absorption solution. Anyway real capacity of the absorption solution is lower (149 $\mathrm{mg} \mathrm{C}$ ) while the absorption solution is replaced when reach conductivity around $2 \mathrm{mS} / \mathrm{cm}$.

At this point the system is opened not only to refill it with the fresh absorption solution but also to provide fresh oxygen. This is realized because the whole system is constructed as a closed system and it is needed to maintain the biodegradation under aerobic condition. If larger amount of organics to study will be considering larger volume of absorption solution needs to be taken into account because of limiting barium hydroxide solubility in water. The apparatus had the air part equal to the liquid part. Used volume of absorption solution is usually 1 litre and the volume used in the reaction bottle is therefore arranged to 0.75 Litres (total volume is 3.6 litre) while the volume of conductivity probe was include in the calculation. Theoretically the capacity of oxygen in this system was calculated to oxidize $195 \mathrm{mg} C$ without opening the system to refill it with fresh oxygen.

\subsection{Interpreting results of biodegradability evaluation}

Because some of organic carbon from the tested substance is incorporated into the new biomass, in the test where the carbon dioxide is used as the main measured parameter it is sufficient to reach $60 \%$ level of biodegradability. The biodegradability is commonly calculated from the amount of biogenicaly produced carbon dioxide according to (6):

$$
D=100 .\left(m_{C_{2} \text { test }}-m_{C_{2} \text { blank }}\right) / \text { ThOC }
$$

Where, ThOC is the carbon input by the application of the test substance in $\mathrm{mg} \mathrm{C}$ and $\mathrm{m}_{\mathrm{CO}_{2}}$ is the amount of carbon bottle or in the blank.

\section{Measuring interface}

\subsection{Conductivity measurement}

Conductivity measurements were executed by Vernier CON-BTA conductivity probes connected to self-developed analogue signal logger or in another words a data acquisition and processing device. The signal logger is a 12 channel microprocessor controlled data acquisition and processing device with RS-485 communication interface. As a human machine interface (HMI) a basic PC with USB port is used. The PC is connected to the communication network through an RS-485/USB converter. Between the data acquisition device and HMI a Master-Slave communication take place, wherein the HMI is the Master node.

A graphical user interface (GUI) was also implemented to the HMI which allows the online monitoring of the measured values and historical data export to xlsx. The developed interface is equipped with SRAM and a super capacitor which together allows the internal measured data storing. This prevents the data loses during the communication failure or the HMI crash. Below, the developed logger is described in more detail. 


\subsection{Analog logger for collecting data from probes measuring degradability of MWF}

Figure 4 shows the block diagram of the proposed analog signal logger. As the input block for connecting sensors, two 13-bit, sigma-delta A/D converters are used. These enables sufficient accuracy for converting measured analog signals to digital signals. The A/D converters can connect up to 12 sensors or probes. Before the A/D conversion, the signal is adjusted to an appropriate range using an operational amplifier. The main microcontroller is galvanically isolated from the input/output circuits up to $1000 \mathrm{~V}$. Thus, ensure confidentiality of sensitive control of the induced (often quite large) voltage. The PIC microcontroller processes the data obtained from the inputs and stores them in the SRAM memory. The data loss from the SRAM during the voltage fail is protected with supercapacitor. The logger is designed to make communication via RS-485 interface which ensures the connection of any PC with USB/RS485 signal converter. The PC is used to visualize the measurement or the data stored in the local database. The HMI user application was developed in Microsoft Visual C development environment.

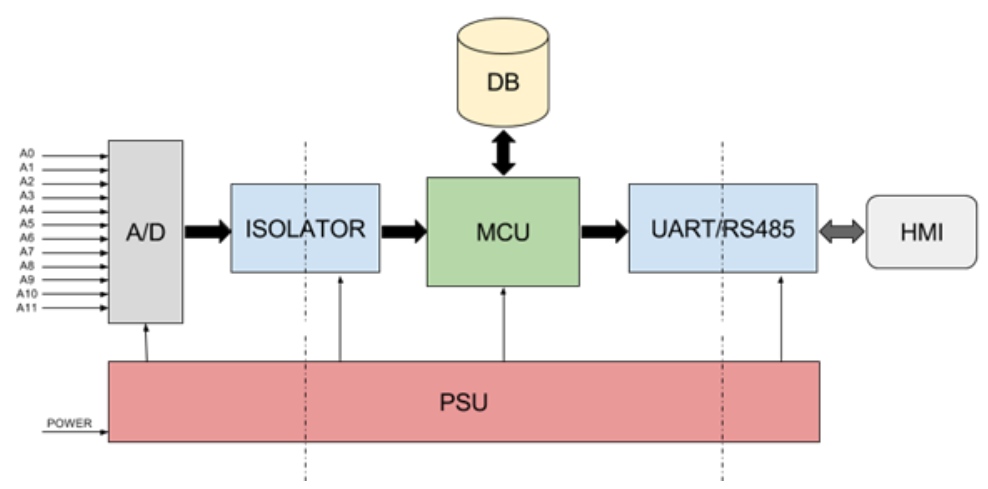

Fig. 4. Block diagram of the analog logger

\subsection{PSU - Power supply unit}

The power supply schematic diagram is shown in Fig. 5.
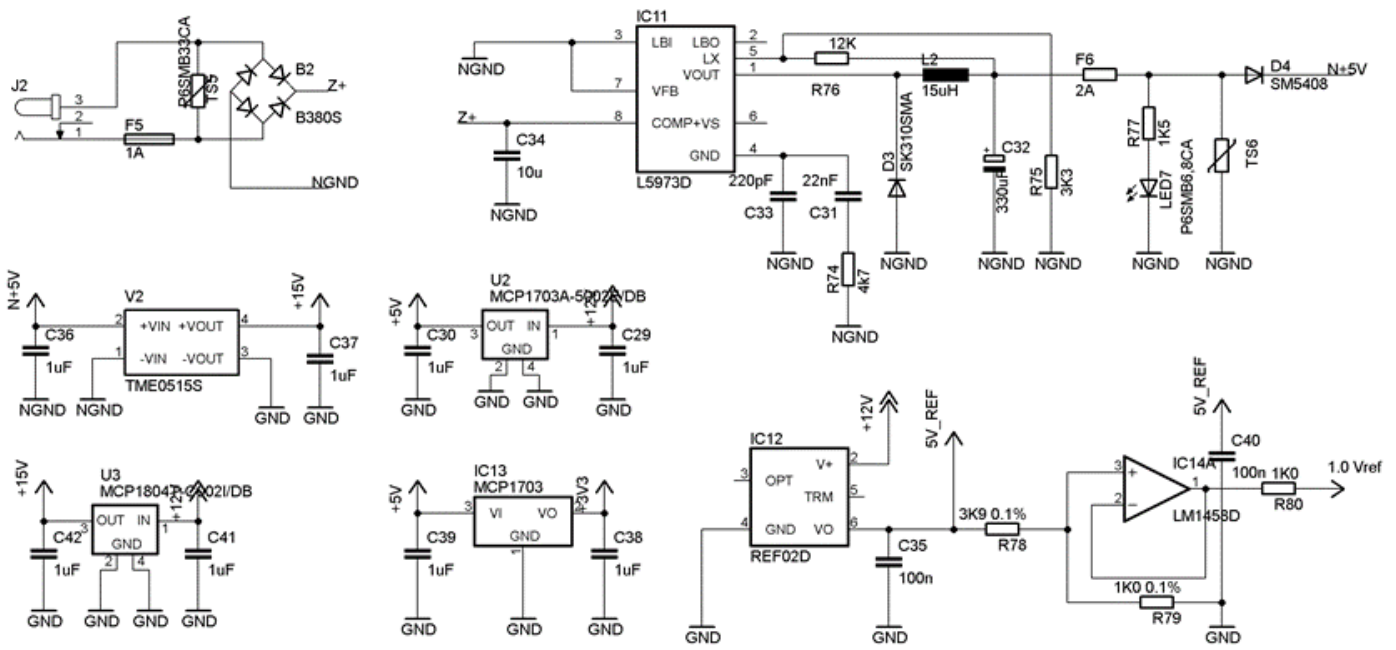

Fig. 5. PS - Power supply

It is designed to ensure the proper voltage and current values for the proposed analog logger. The voltage values depend on the part of the system for which it is supplied and it is controlled by the voltage regulators and converters used in the power supply. Input voltage could vary from 9 to $35 \mathrm{~V}$ AC or DC. The AC or DC input voltage is linked thru the rectifier B2 to IC11. The L5973D is a step down monolithic power switching regulator with a minimum switch current limit of 2.5 A so it is able to deliver more than $2 \mathrm{~A}$ DC current to the load depending on the application conditions. The output voltage can be set from $1.235 \mathrm{~V}$ to $35 \mathrm{~V}$ and in this case it is set to $6 \mathrm{~V}$. A voltage divider is required to adjust the output voltage. The output voltage is set by a following formula (7):

$$
V_{\text {OUT }}=1,3 \cdot \frac{R 76+R 75}{R 75} \cdot V_{F B}
$$


Where, R76 is the resistor connected between the output voltage and the feedback pin, R75 is the resistor between the feedback pin and ground, VFB is the Feedback voltage VOUT is the output voltage. The high current level is also achieved thanks to an SO8 package with exposed frame, that allows to reduce the Rth(j-amb) down to approximately $40{ }^{\circ} \mathrm{C} / \mathrm{W}$. The device uses an internal P-channel D-MOS transistor (with a typical Rdson of $250 \mathrm{~m} \Omega$ ) as switching element to minimize the size of the external components. An internal oscillator fixes the switching frequency at $250 \mathrm{kHz}$. Having a minimum input voltage of $4 \mathrm{~V}$ only, it is particularly suitable for $5 \mathrm{~V}$ bus, available in all computer related applications. Pulse by pulse current limit with the internal frequency modulation offers an effective constant current short circuit protection. [8] [1] The output voltage from IC11 is with the TME0515 (V2) galvanically isolated from the other parts of the system. The TME0515 is sub-miniature, isolated DC/DC-converters in a SIP-package, which requires only $0.7 \mathrm{~cm} 2$ of board space. They provide a cost effective solution to generate supplementary, isolated voltages. [9] [2] After the isolation the voltage value is adapted for the special needs of the control circuit. The adaptation is accomplished by three voltage regulators and one voltage reference. The MCP1703 (U2, IC13) is a family of CMOS low dropout (LDO) voltage regulators that can deliver up to $250 \mathrm{~mA}$ of current while consuming only $2.0 \mu \mathrm{A}$ of quiescent current. The input operating range is specified from $2.7 \mathrm{~V}$ to $16.0 \mathrm{~V}$. The MCP1703 is capable of delivering $250 \mathrm{~mA}$ with only $625 \mathrm{mV}$ (typical) of input to output voltage differential (VOUT $=2.8 \mathrm{~V}$ ). The output voltage tolerance of the MCP1703 is typically $\pm 0.4 \%$ at $+25^{\circ} \mathrm{C}$ and $\pm 3 \%$ maximum over the operating junction temperature range of $-40^{\circ} \mathrm{C}$ to $+125^{\circ} \mathrm{C}$. Line regulation is $\pm 0.1 \%$ typical at $+25^{\circ} \mathrm{C}$. Output voltages available for the MCP1703 range from $1.2 \mathrm{~V}$ to $5.5 \mathrm{~V}$. The LDO output is stable when using only $1 \mu \mathrm{F}$ of output capacitance. Ceramic, tantalum, or aluminium electrolytic capacitors can all be used for input and output. Overcurrent limit and over temperature shutdown provide a robust solution for any application. [10] [3] The MCP1804 (U3) is a CMOS low dropout (LDO) voltage regulator that can deliver up to $150 \mathrm{~mA}$ of current while consuming only $50 \mu \mathrm{A}$ of quiescent current (typical, $1.8 \mathrm{~V}<\mathrm{VOUT}>5.0 \mathrm{~V}$ ). The input operating range is specified from $2.0 \mathrm{~V}$ to $28.0 \mathrm{~V}$. The MCP1804 is capable of delivering $100 \mathrm{~mA}$ with only $1300 \mathrm{mV}$ (typical) of input to output voltage differential $\left(\right.$ VOUT $=3.3 \mathrm{~V}$ ). The output voltage tolerance of the MCP1804 at $+25^{\circ} \mathrm{C}$ is a maximum of $\pm 2 \%$. Line regulation is $\pm 0.15 \%$ typical at $+25^{\circ} \mathrm{C}$. The LDO input and output is stable with $0.1 \mu \mathrm{F}$ of input and output capacitance. Ceramic, tantalum or aluminium electrolytic capacitors can all be used for input and output. Overcurrent limit with current foldback to $40 \mathrm{~mA}$ (typical) provides short circuit protection. A shutdown (SHDN) function allows the output to be enabled or disabled. When disabled, the MCP1804 draws only $0.01 \mu \mathrm{A}$ of current. [11] [4] The REF02 (IC12) precision voltage reference provides a stable $5 \mathrm{~V}$ output that can be adjusted over a $\pm 6 \%$ range with minimal effect on temperature stability. Single-supply operation over an input voltage range of $7 \mathrm{~V}$ to $40 \mathrm{~V}$, low current drain of $1 \mathrm{~mA}$, and excellent temperature stability are achieved with an improved band gap design. Low cost, low noise and low power make the REF02 an excellent choice whenever a stable voltage reference is required. Applications include DACs and ADCs, portable instrumentation, and digital voltmeters. In our case the $5 \mathrm{~V}$ output was decreased to $1 \mathrm{~V}$ with a general purpose operation amplifier LM1458 (IC14A). The 1V is used as a reference for the AD converters used in the logger.[12] [5].

\subsection{MCU - Microcontroller unit}

The main circuit (Fig. 6) consists of one Microchip PIC microprocessor (IC15) and two memories (IC17, IC16).

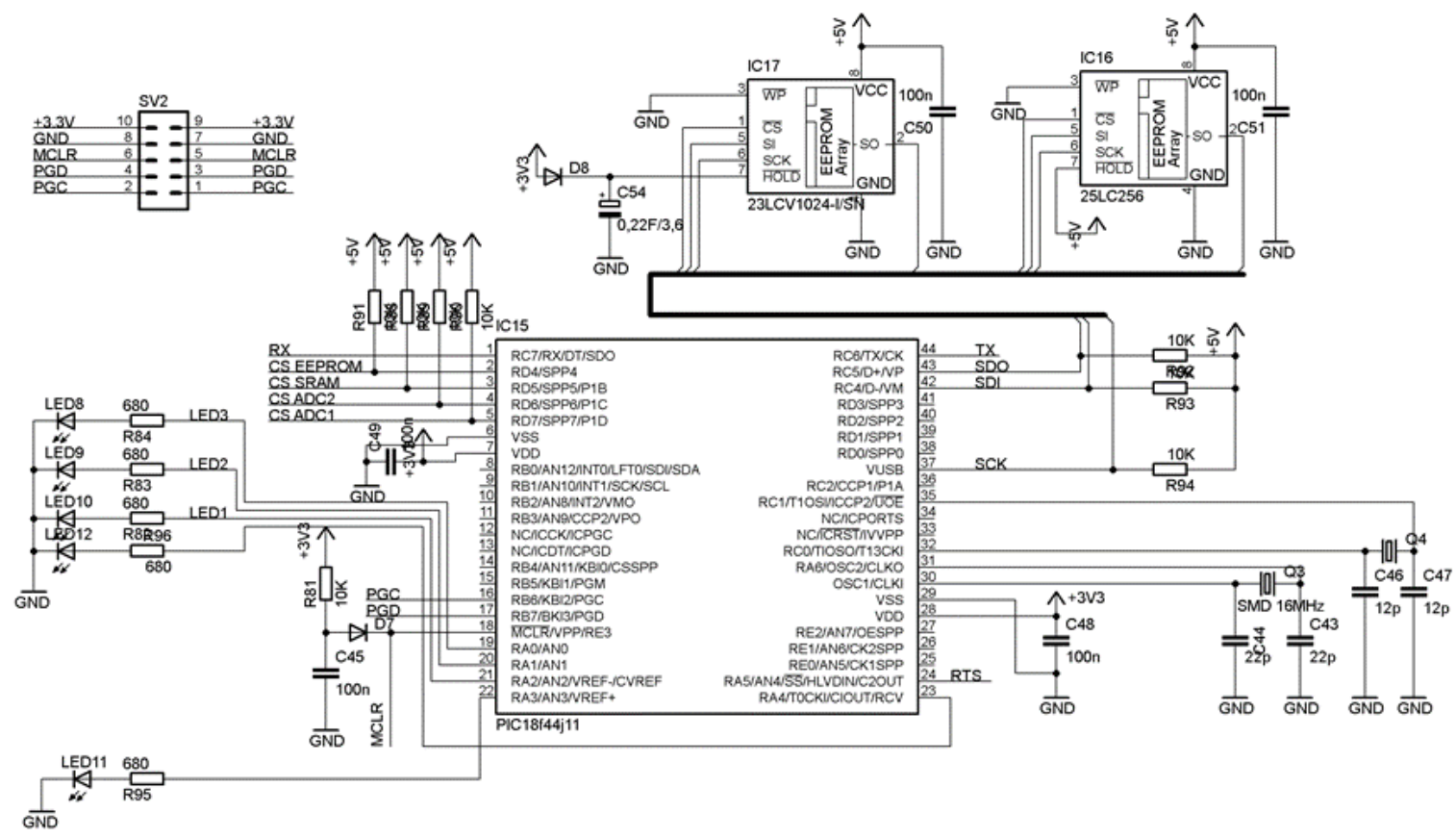

Fig. 6. Microcontroller unit 
The PIC18F44J11 provides low power and high performance 8-bit MCU with peripheral flexibility in a small package for cost sensitive applications. New features include Deep sleep mode for low power applications, peripheral pin Select for design flexibility for mapping peripherals to I/O pins and a CTMU module for easy capacitive touch user interfaces. The PIC18F44J11 family is ideal for applications requiring cost-effective, low-power solutions with a robust peripheral set in a small package.[13] [6] The MCU stores the measured data in SRAM (IC17). The 23LCV1024 (IC17) is a 1 Mbit Serial SRAM device (DB). The memory is accessed via a simple Serial Peripheral Interface (SPI) compatible serial bus. The bus signals required are a clock input (SCK) plus separate data in (SI) and data out (SO) lines. Access to the device is controlled through a Chip Select (CS) input. Additionally, SDI (Serial Dual Interface) is supported if your application needs faster data rates. This device also supports unlimited reads and writes to the memory array, and supports data backup via an external battery/coin cell connected to VBAT (pin 7). The VBAT pin is connected to 0,22F supercapacitor. The 23LCV1024 contains an 8-bit instruction register. The device is accessed via the SI pin, with data being clocked in on the rising edge of SCK. The CS pin is low for the entire operation. [14] [7] The configuration of the logger is stored in serial EEPROM (IC16). The 25LC256 is 256 Kbit Serial Electrically Erasable PROMs. The memory is accessed via a simple Serial Peripheral Interface (SPI) compatible serial bus. The bus signals required are a clock input (SCK) plus separate data in (SI) and data out (SO) lines. Access to the device is controlled through a Chip Select (CS) input. Communication to the device can be paused via the hold pin (HOLD). While the device is paused, transitions on its inputs will be ignored, with the exception of Chip Select, allowing the host to service higher priority interrupts. [15] [8]

\subsection{A/D - Analog to digital converter}

The probes used in the system of MWF degradability measurement are connected to analog inputs of the designed logger. The analog signal is converted to digital signal which can be already processed by the MCU. For the conversion two A/D converters (IC19, IC20) are used (Fig. 7).

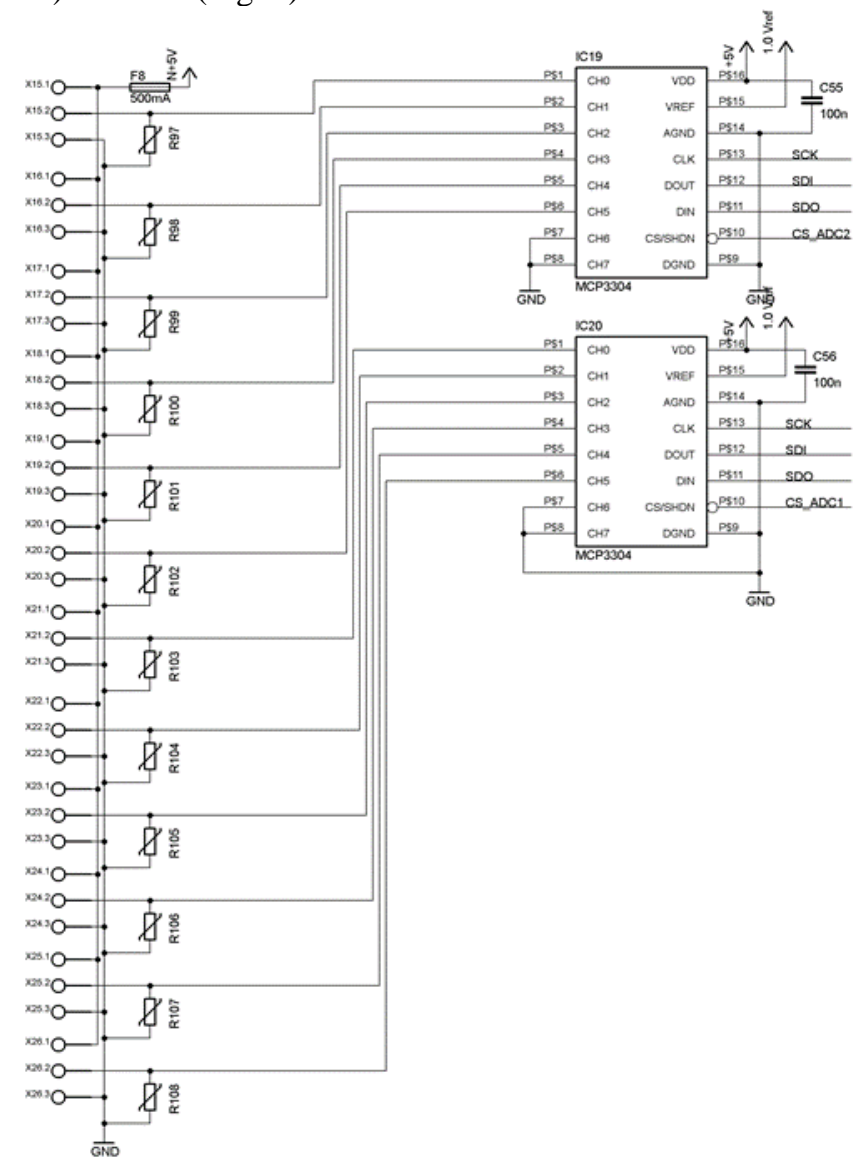

Fig. 7. A/D converters for connecting measuring probes

MCP3304 13-bit A/D converter features full differential inputs and low-power consumption in a small package that is ideal for battery powered systems and remote data acquisition applications. The MCP3304 is programmable and provides four differential input pairs or eight single ended inputs. Incorporating a successive approximation architecture with on-board sample and hold circuitry, these 13-bit A/D converters are specified to have \pm 1 LSB Differential Nonlinearity (DNL); \pm 1 LSB Integral Nonlinearity (INL) for B-grade and \pm 2 LSB for C-grade devices. The industrystandard SPI serial interface enables 13-bit A/D converter capability to be added to any PIC microcontroller. 
The MCP3304 device features low current design that permits operation with typical standby and active currents of only $50 \mathrm{nA}$ and $300 \mu \mathrm{A}$, respectively. The devices operate over a broad voltage range of $2.7 \mathrm{~V}$ to $5.5 \mathrm{~V}$ and are capable of conversion rates of up to $100 \mathrm{ksps}$. The reference voltage can be varied from $400 \mathrm{mV}$ to $5 \mathrm{~V}$, yielding input-referred resolution between $98 \mu \mathrm{V}$ and $1.22 \mathrm{mV}$. The full differential inputs of these devices enable a wide variety of signals to be output code format is a binary two's complement scheme (Fig. 8), with a leading sign bit that indicates the sign of the output. If the IN+ input is higher than the IN input, the sign bit will be a zero. If the IN- input is higher, the sign bit will be a ' 1 '.

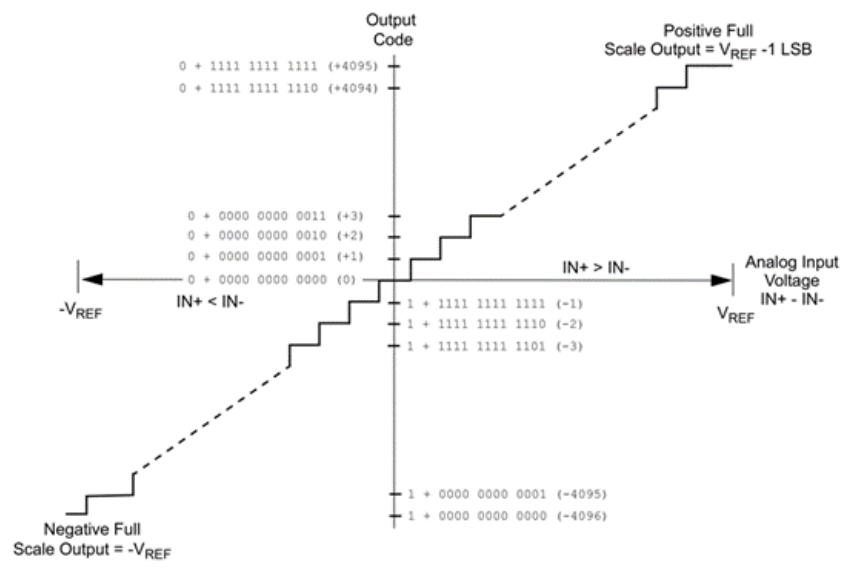

Fig. 8. Output code transfer function

The diagram shown in Figure 8 shows the output code transfer function. In this diagram, the horizontal axis is the analog input voltage and the vertical axis is the output code of the ADC. It shows that when IN+ is equal to IN-, both the sign bit and the data word is zero. As IN+ gets larger with respect to IN-, the sign bit is a zero and the data word gets larger. The full scale output code is reached at +4095 when the input [(IN+) - (IN-)] reaches VREF - 1 LSB. When IN- is larger than IN+, the two's complement output codes will be seen with the sign bit being a one [16].

\subsection{Materials and methods}

For the calibration (conductivity change of absorption solution according to trapped carbon dioxide) a defined amount of carbon dioxide was prepared by the chemical reaction between standard solution of sodium carbonate and hydrochloric acid. A defined volume of $\mathrm{Na} 2 \mathrm{CO} 3(1 \mathrm{~mol} / \mathrm{L})$ was added to $50 \mathrm{ml}$ of $\mathrm{HCl}(2 \mathrm{~mol} / \mathrm{L})$ while the air part was continuously pumped to the absorption solution. The absorption bottle during calibration contained 1 Liter of $\mathrm{Ba}(\mathrm{OH})_{2}(0.02 \mathrm{~mol} / \mathrm{L})$ for the measuring range $0-20 \mathrm{mS} / \mathrm{cm}$ and diluted solution for the measuring range $0-2 \mathrm{mS} / \mathrm{cm}$. When the conductivity decreasing stabilized at the same level another defined volume of sodium carbonate solution was added into acid. Final calibrating curves are displayed in the Fig. 2 for both of the conductivity probes measuring ranges $(0-2 \mathrm{mS} / \mathrm{cm}$ and $0-20$ $\mathrm{mS} / \mathrm{cm}$ ). Higher range was used in the testing biodegradability of real samples (glucose) and lower range was used in the case of blank measurement. Concentration of barium hydroxide was during the test set up to $0.0175 \mathrm{~mol} / \mathrm{L}$ as it is defined in [1]. Conductivity probes were calibrated according to standardized conductivity solution of potassium chloride $(0.01$ $\mathrm{mol} / \mathrm{L}$ and $0.10 \mathrm{~mol} / \mathrm{L}$ ) as a two point calibration. For recording data from all conductivity probes it was used selfdeveloped interface discussed in the previous text. The sampling period of the logger was set to 30 minutes.

Reaction bottle obtained $750 \mathrm{~mL}$ mixture made of mineral medium, defined amount of activated sludge and tested substance all diluted with distilled water according to [1]. Activated sludge used as an inoculum was collected from the sewage treatment plant Zeleneč treating predominantly municipal water and before use prepared according to [2]. Concentration was set up to $0.10 \mathrm{~g} / \mathrm{L}$ of suspended solids. As a standard substance for the biodegradability measuring was used glucose. All chemicals used were analytical grade without further purification. Air used in the apparatus during the test was not cleaned from the presence $\mathrm{CO}_{2}$ as it is realized in [5] standardized test, but the same level was occurred also in blank.

\section{Results and discussion}

The proposed analog logger was tested in real biodegradability test of a standard substance - glucose. The duration of the test was up to 2 weeks of uninterrupted measurement. Figure 9a display results of recorded conductivity in 8 used biodegradability apparatuses. As it is seems from the graphs there are two obvious breaks in recorded conductivity of glucose 280 and $240 \mathrm{ppm} \mathrm{C}$ on the 5th day of cultivation and glucose 200 and $160 \mathrm{ppm} \mathrm{C}$ during the 7 th day of cultivation. It means that the absorption solution were closer to its capacity (conductivity of absorption solution was in the range 2-4 $\mathrm{mS} / \mathrm{cm}$ ) so the bottle was refilled with the fresh solution of barium hydroxide. While the blank was not opened at the same time, this enlarging the capacity of trapped carbon dioxide brings some uncertainty because of carbon dioxide occurred in the air. 


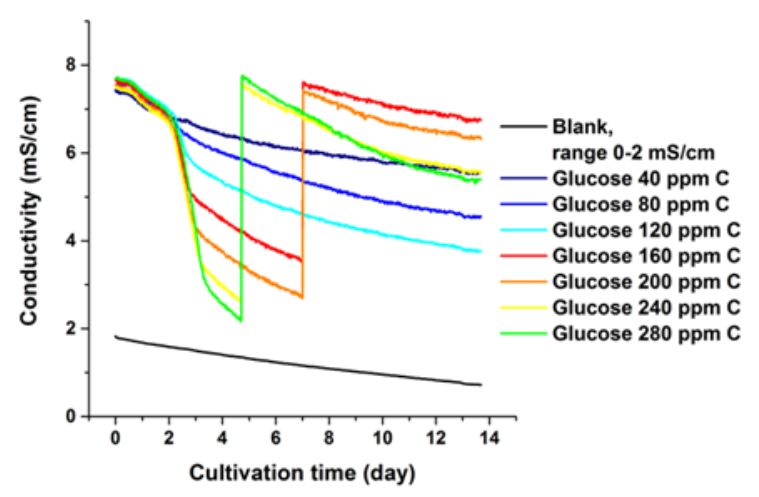

a)

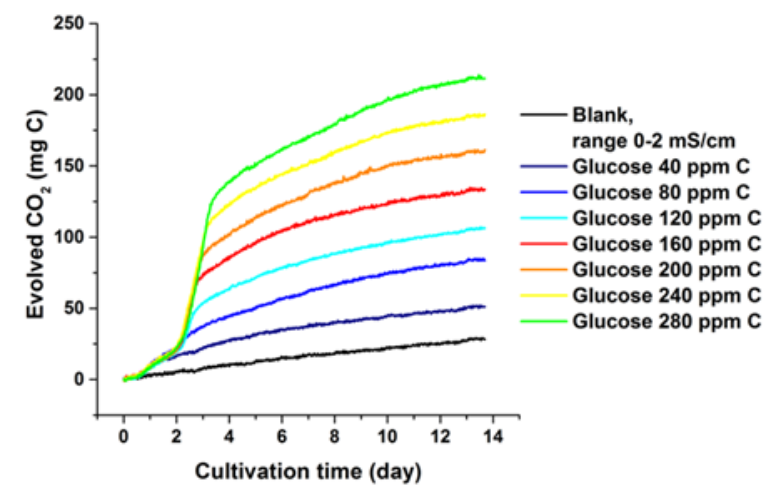

b)

Fig. 9. Collected data (a Conductivity record of Glucose, b Carbon dioxide evolved by the microorganisms calculated from the recorded conductivity)

Figure 9b depict calculated results for the total evolved carbon dioxide according to (4) and (5). Amount of produced carbon dioxide arise more as the amount of organic carbon source becoming from the tested substance glucose is higher. All tested standards reach the level of $60 \%$ biodegradability (Fig. 10) before the 10th day of the test so they fully reflect the basic condition of standardized OECD 301B test and may be labelled as fully readily biodegradable. On the 14th day of the test, samples of glucose $80-280 \mathrm{ppm}$ reach the level of $80 \%$. All of them are close to plateau phase so no following degradation will be observed. This is because glucose was fully utilized by microorganisms and a part of organic carbon was incorporated into a new biomass and therefore was not converted into evolved carbon dioxide. Anyway the lowest tested concentrations (glucose $40 \mathrm{ppm} \mathrm{C}$ and glucose $80 \mathrm{ppm} \mathrm{C}$ ) exhibit a large noise in the final calculated value of the biodegradability. This is explained by the low total decrease in conductivity of absorption solution. While the decrease in the conductivity is less than $2 \mathrm{mS} / \mathrm{cm}$ in glucose $40 \mathrm{ppm} \mathrm{C}$ it is recommended to use the lower range of conductivity probes $(0-2 \mathrm{mS} / \mathrm{cm})$ together with appropriate concentration of absorption solution. This fact set the lower limit of the biodegradability determination to samples with higher tested concentration of organics up to $120 \mathrm{ppm} \mathrm{C}$ for the measuring range of probes $0-20 \mathrm{mS} / \mathrm{cm}$. When testing of substances with lower concentration is taken into account (under 80 ppm C) it is recommended to use the lower range of conductivity probes.

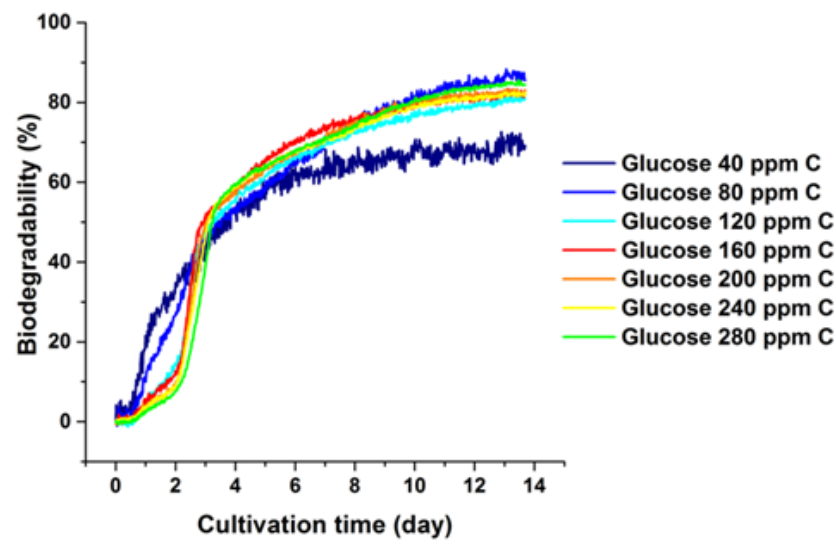

Fig. 10. Biodegradability curves

\section{Conclusion}

Developed interface was successfully tested in the real biodegradability measurement of glucose and showed its applicability. It brings reduction of manual time consuming measurements in carbon dioxide analysis, while make possible real-time control of biodegradability test which may last 14-28 days. Implementation of noise reducing functions might be very useful. Possibilities in reducing the noise will be a part of the following research. While switching from lower to higher range is manual, followed development of the interface will be focused on the possible automation of this part or change probes from VERNIER to other more accurate probes of other producer. Followed development will focus on enlarging capacity to not opening the apparatus during the test and possibility to fill the input environment with the air cleaned from the occurred carbon dioxide.

Collected knowledge will be used to dispose used MWFs from milling and turning machines. Future development will focus to ensure the same properties of cutting fluids in the process of testing cutting tools for hard-to-machinable materials. 


\section{Acknowledgments}

The article was written with the support of the project of VEGA grant agency of the Ministry of Education, Science, Research and Sport of the Slovak Republic and Slovak Academy of Sciences, no. 1/0097/17: "The research of novel method for cutting edge preparation to increase the tool performance in machining of difficult-to-machine materials", project and APVV Project of Slovak Research and development Agency of the Ministry of Education, Science, Research and Sport of the Slovak Republic, no. APVV-16-0057: "Research into the Unique Method for Treatment of Cutting Edge Microgeometry by Plasma Discharges in Electrolyte to Increase the Tool Life of Cutting Tools in Machining of Difficultto-Machine Materials."

\section{References}

[1] Norr, C., Meinecke, S., Brackemann, H. Modification of the Zahn - Wellens test: determination of the biodegradability of poorly soluble, adsorbing and volatile substances by measurement of oxygen consumption and carbon dioxide production, Chemosphere. 44 (2001) 553-559.

[2] Oecd 301 B, Guideline For Testing Of Chemicals Adopted by the Council on 17th July 1992 Ready Biodegradability, (1992).

[3] Council Regulation (EC) No 440/200, of 30 May 2008 laying down test methods pursuant to Regulation (EC) No $1907 / 2006$ of the European Parliament and of the Council on the Registration, Evaluation, Authorisation and Restriction of Chemicals (REACH), (2008).

[4] ASTM D 6139-11, (2011). Standard Test Method for Determining the Aerobic Aquatic Biodegradation of Lubricants or Their Components Using the Gledhill Shake Flask.

[5] ASTM D 5864-11, (2011). Standard Test Method for Determining Aerobic Aquatic Biodegradation of Lubricants or Their Components.

[6] Muminovic, A., Repcic, N., Colic, M. (2014). Thermo Elasto Hydrodynamic Lubrication Model of Mixed Friction. 24th DAAAM International Symposium on Intelligent Manufacturing and Automation. In Procedia Engineering 69, (2014.), p. 49 - 56, ISSN: 1877-7058.

[7] Strotmann, U., Reuschenbach, P., Schwarz, H., Pagga, U. (2004). Development and evaluation of an online CO(2) evolution test and a multicomponent biodegradation test system., Appl. Environ. Microbiol. 4621-4628. doi:10.1128/AEM.70.8.4621-4628.2004.

[8] STMicroelectronics, (2008). AN1518 Application note, Designing with the 2.5 A DC-DC converter L5973D, 30.

[9] Traco Electronic AG, (2010). DC/DC Converters TME Series, 1 Watt, 3. www.tracopower.com.

[10] Microchip Technology, (2010). Datasheet: MCP1703. 250 mA, 16V, Low Quiescent Current LDO Regulator, 28. http://ww1.microchip.com/downloads/en/DeviceDoc/22049e.pdf.

[11] Microchip Technology, (2013). Datasheet: MCP1804. $150 \mathrm{~mA}, 28 \mathrm{~V}$ LDO Regulator With Shutdown, 36. http://ww1.microchip.com/downloads/en/DeviceDoc/20002200D.pdf.

[12] Analog Devices, (2005). 5 V Precision Voltage Reference / Temperature Transducer, REF02, 16. www.analog.com.

[13] Microchip Technology, (2009) PIC18F46J11 Family Data Sheet, 28/44-Pin, Low-Power, High-Performance $\begin{array}{lllll}\text { Microcontrollers } & \text { with } & \text { XLP } & \text { Technology, }\end{array}$ http://ww1.microchip.com/downloads/en/devicedoc/39932c.pdf.

[14] Microchip Technology, (2012) Datasheet: 23LCV1024. 1 Mbit SPI Serial SRAM with Battery Backup and SDI Interface, 30. http://ww1.microchip.com/downloads/en/DeviceDoc/25156A.pdf.

[15] Microchip Technology, (2013) Datasheet: 25AA256/25LC256. 256K SPI Bus Serial EEPROM, 32. http://ww1.microchip.com/downloads/en/DeviceDoc/21822G.pdf.

[16] Microchip Technology, (2008) Datasheet: MCP3304. 13-Bit Differential Input, Low Power A/D Converter with SPI Serial Interface, 46. http://ww1.microchip.com/downloads/en/DeviceDoc/21697e.pdf. 